University of Windsor

Scholarship at UWindsor

\title{
Profound barriers to basic cancer care most notably experienced by uninsured women: Historical note on the present policy considerations
}

\author{
Amy M. Alberton \\ University of Windsor \\ Kevin M. Gorey \\ University of Windsor
}

Follow this and additional works at: https://scholar.uwindsor.ca/socialworkpub

Part of the Community Health and Preventive Medicine Commons, Digestive System Diseases Commons, Epidemiology Commons, Geography Commons, Health Policy Commons, Health Services Research Commons, Inequality and Stratification Commons, Neoplasms Commons, Political Science Commons, Social Policy Commons, Social Welfare Commons, Social Work Commons, and the Women's Studies Commons

\section{Recommended Citation}

Alberton, Amy M. and Gorey, Kevin M.. (2017). Profound barriers to basic cancer care most notably experienced by uninsured women: Historical note on the present policy considerations. Social Work in Health Care, Epub ahead of print.

https://scholar.uwindsor.ca/socialworkpub/56

This Article is brought to you for free and open access by the School of Social Work at Scholarship at UWindsor. It has been accepted for inclusion in Social Work Publications by an authorized administrator of Scholarship at UWindsor. For more information, please contact scholarship@uwindsor.ca. 


\section{Profound barriers to basic cancer care most notably experienced by uninsured women: Historical note on the present policy considerations}

\section{Amy M Alberton \& Kevin M Gorey}

To cite this article: Amy M Alberton \& Kevin M Gorey (2017) Profound barriers to basic cancer care most notably experienced by uninsured women: Historical note on the present policy considerations, Social Work in Health Care, 56:10, 943-949, DOI: 10.1080/00981389.2017.1373724

To link to this article: http://dx.doi.org/10.1080/00981389.2017.1373724

曲 Published online: 07 Sep 2017.

Submit your article to this journal $[\pi$

Џ Article views: 44

Q View related articles $\sqsubset$

View Crossmark data \lceil 


\title{
Profound barriers to basic cancer care most notably experienced by uninsured women: Historical note on the present policy considerations
}

\author{
Amy M Alberton, MSW (i) and Kevin M Gorey, PhD (D) \\ School of Social Work, University of Windsor, Windsor, Ontario, Canada
}

\begin{abstract}
America is considering the replacement of Obamacare with Trumpcare. This historical cohort revisited pre-Obamacare colon cancer care among people living in poverty in California $(N=5,776)$. It affirmed a gender by health insurance hypothesis on nonreceipt of surgery such that uninsured women were at greater risk than uninsured men. Uninsured women were three times as likely as insured women to be denied access to such basic care. Similar men were two times as likely. America is bound to repeat such profound health care inequities if Obamacare is repealed. Instead, Obamacare ought to be retained and strengthened in all states, red and blue.
\end{abstract}

\section{ARTICLE HISTORY}

Received 11 May 2017

Revised 2 August 2017

Accepted 26 August 2017

\section{KEYWORDS}

Colon cancer care; gender; health care policy; health care reform; historical cohort; intersectionality; interaction effect; Patient Protection and Affordable

Care Act; structural

inequality; uninsured

Various health care acts or Trumpcare are being considered to replace the Affordable Care Act (ACA) or Obamacare. If any pass they would increase the ranks of the uninsured and decrease the benefits of all, but the wealthiest Americans while increasing their out-of-pocket costs. People living in poverty would suffer the most, especially the Medicaid-eligible or near-eligible in so-called red states. Our profession has a tradition of advocating for quality health care for all and we are again called to action (Gorin, 2017; National Association of Social Workers, 2009). This study revisits pre-Obamacare cancer care and reminds us of the profound barriers to basic care that were experienced by uninsured people, especially women in the USA.

Canada and the USA share a 5,000 kilometer border and many social and economic characteristics, but provide health care in distinct ways. Canada provides universal access to care via a single, public payer, while the USA provides no such guarantee via multiple payers, private and public, historically leaving tens of millions Americans uninsured (DeNavas-Walt, Proctor, \& Smith, 2011). This natural policy laboratory presents compelling opportunities to learn from each other. The first Canada-USA study of four major cancer types was sponsored by the General Accounting Office during the George H. W. Bush administration (Keller, Peterson, \& Silberman, 1997). It tended to mute enthusiasm for Canada- 
like solutions to America's health care problems as it found no practical survival differences between the two countries. Otherwise well designed, it did not account for socioeconomic factors. Our research group thought such comparisons of national "haystacks" tended to lose important "needles" of knowledge. Consider the diversity of people and places in Canada and the USA: women and men, uninsured to well-insured, residing in high poverty to affluent neighborhoods and so on. Overall comparisons of the average effects of countries are bound to miss knowledge about the unique experiences of important subpopulations. We studied breast and colon cancer care in impoverished places in Ontario and California over the past two decades and observed large Canadian advantages on treatment access and survival. In fact, the more impoverished the people or places the larger were the Canadian advantages that were largely explained by their better health insurance coverage (Gorey, Hamm, Luginaah, Zou, \& Holowaty, 2017; Gorey et al., 1997). Focusing on the experiences of socioeconomically vulnerable people in vulnerable places seems to magnify clinical and policy significance. This study adds evidence particularly relevant to the unique experiences of uninsured women living in poverty.

Colon cancer care, a common and treatable form of cancer, was studied among those living in poverty in 1990s and 2000s California (Gorey et al., 2011, 2013, 2015). Similar people were originally studied in Ontario. They were excluded from this analysis as no socioeconomic gradients were observed in their care. These historical California cohorts found disadvantages among people living in poverty that were largely accounted for by health insurance inadequacies across the care continuum from waiting times for initial surgical treatment through receipt of chemotherapy to survival. Chemotherapy was preferentially studied as there was much managerial and clinical discretion in its use. However, there was little such discretion in surgical care. Surgical removal of the tumor is the first indicated treatment for nearly all with colon cancer. Most people studied received such a colectomy (93\% to 98\%). Preliminary analyses suggested that the uninsured may be at grave risk of its nonreceipt and that women may be at greater risk than men (Campbell et al., 2016; Levitz et al., 2015). This secondary analysis explored that novel gender by health insurance hypothesis.

\section{Methods}

A cancer registry-based colon cancer cohort of 6,300 people was established in California between 1995 and 2000, joined to the 2000 census and followed until enactment of the ACA. The original study oversampled people living in poverty, randomly selecting a third of its participants from high poverty neighborhoods where $30 \%$ or more of the households were poor (Wilson, 2012). The remainder were selected from strata of $5-29 \%$ or $<5 \%$ poor. This secondary analysis was restricted to 5,466 insured and 310 uninsured people with staged colon cancer. 
2,604 were privately and 2,862 publicly insured: Medicare (2,601) or Medicaid (261).

Age can confound any cancer analysis and surgery is indicated therapeutically for stages I-III or palliatively for stage IV colon cancer. A logistic regression tested main effects and the hypothesized interaction (Hosmer, Lemeshow, \& Sturdivant, 2013). Their significance was estimated after controlling for age and stage of disease with odds ratios (OR). All rates were directly and internally age and stage-adjusted and reported as percentages. Standardized rate ratios (RR) and rate differences $(\mathrm{RD})$ were reported with 95\% confidence intervals (CI). Further methodological details were published (Gorey et al., 2011, 2013, 2015).

\section{Results}

Samples are described in Table 1. First, low representation of the uninsured may seem surprising (5\%). Hospital social workers work to connect uninsured people with colon cancer to Medicaid or Medicare. Second, the uninsured were a decade younger than the insured: mean ages of 59 and $70 ; t(5,774)=11.41, p<.05$. Not surprisingly, the uninsured were twice as likely to have never been married (22\% vs $10 \%)$. The uninsured were also more likely to live in high poverty neighborhoods and to be ethnic minority or racialized people of color. They were twice as likely to

Table 1. Descriptions of 5,466 insured and 310 uninsured people with colon cancer.

\begin{tabular}{lrrrr}
\hline & \multicolumn{2}{c}{ Insured, No. (\%) } & \multicolumn{2}{c}{ Uninsured, No. (\%) } \\
\hline Age at diagnosis* & & & & \\
$25-59$ & 1,096 & 20.1 & 160 & 51.6 \\
$60-69$ & 1,220 & 22.3 & 82 & 26.5 \\
$70-79$ & 1,758 & 32.2 & 44 & 14.2 \\
$\geq 80$ & 1,392 & 25.5 & 24 & 7.7 \\
Women & 2,875 & 52.6 & 146 & 47.1 \\
Marital status* & & & & \\
$\quad$ Married & 3,010 & 55.1 & 147 & 47.4 \\
Never married & 558 & 10.2 & 69 & 22.3 \\
Separated or divorced & 499 & 9.1 & 40 & 12.9 \\
Widowed & 1,291 & 23.6 & 32 & 10.3 \\
Missing data & 108 & 2.0 & 22 & 7.1 \\
Ethnicity or racialized group* & & & & \\
Non-Hispanic white & 3,724 & 68.1 & 153 & 49.4 \\
Non-Hispanic black & 578 & 10.6 & 32 & 10.3 \\
Hispanic & 660 & 12.1 & 75 & 24.2 \\
Asian or Pacific Islander & 468 & 8.6 & 42 & 13.5 \\
Other & 36 & 0.6 & 8 & 2.6 \\
Neighborhood poverty prevalence (\%)* & & & & \\
$\quad$ < & 1,889 & 34.6 & 70 & 22.6 \\
5 - 29 & 1,829 & 33.5 & 94 & 30.3 \\
Z30 & 1,748 & 32.0 & 146 & 47.1 \\
Stage at diagnosis* & & & & \\
I & 1,248 & 22.8 & 52 & 16.8 \\
II & 1,791 & 32.8 & 91 & 29.4 \\
III & 1,314 & 24.0 & 78 & 25.2 \\
IV & 1,113 & 20.4 & 89 & 28.7 \\
\hline
\end{tabular}

* Health insurance group differences were statistically significant $\left(\chi^{2}\right.$ test, $\left.p<.05\right)$. 
be Hispanic (24\% vs $12 \%$ ). Finally, the uninsured tended to have more advanced disease.

Regression observed a significant effect of being uninsured ( $O R=3.20$ ), no effect of gender and, as hypothesized, a significant gender by health insurance interaction. Together they accounted for nearly half of surgery nonreceipts (46\%). Ethnicity/race did not enter the regression. Poverty and marital status did $(p<.05)$, but were not practically significant. They only explained $0.5 \%$ more nonreceipts. The main and interacting effects of gender and health insurance are practically depicted in Table 2. There was no main effect of gender. Overall, women and men had nearly identical surgery nonreceipt rates. However, there was an extremely large main effect of being uninsured. Relative to the insured, they experienced approximately three times the risk $(R R=2.83)$. In fact, one of every five uninsured people did not receive surgery. The interaction in the bottom of the table depicts great risk among uninsured men $(R R=2.30)$, but even greater risk among uninsured women $(\mathrm{RR}=3.34)$.

Description of interaction strata aided interpretation. Among the insured, men were more likely to be privately insured (52\% vs $43 \%)$ and to be married ( $71 \%$ vs $42 \%) ; \chi^{2}(1)=40.72$ and $\chi^{2}(1)=452.60$, both $p<.05$. But among the uninsured, women were more likely to be unmarried (55\% vs $43 \%$ ); $\chi^{2}(1)=3.96, p<.05$. Married men clearly had greatest access to employment-based health insurance. Finally, there can be legitimate reasons for refusing surgery. Among the insured, $8 \%$ refused surgery, but this refusal rate did not differ by gender. Few of the uninsured refused surgery (2\%) and again, this rate was the same for women and men.

Table 2. Main effects and interaction of gender and health insurance on non-receipt of colon cancer surgery $(N=5,776)$.

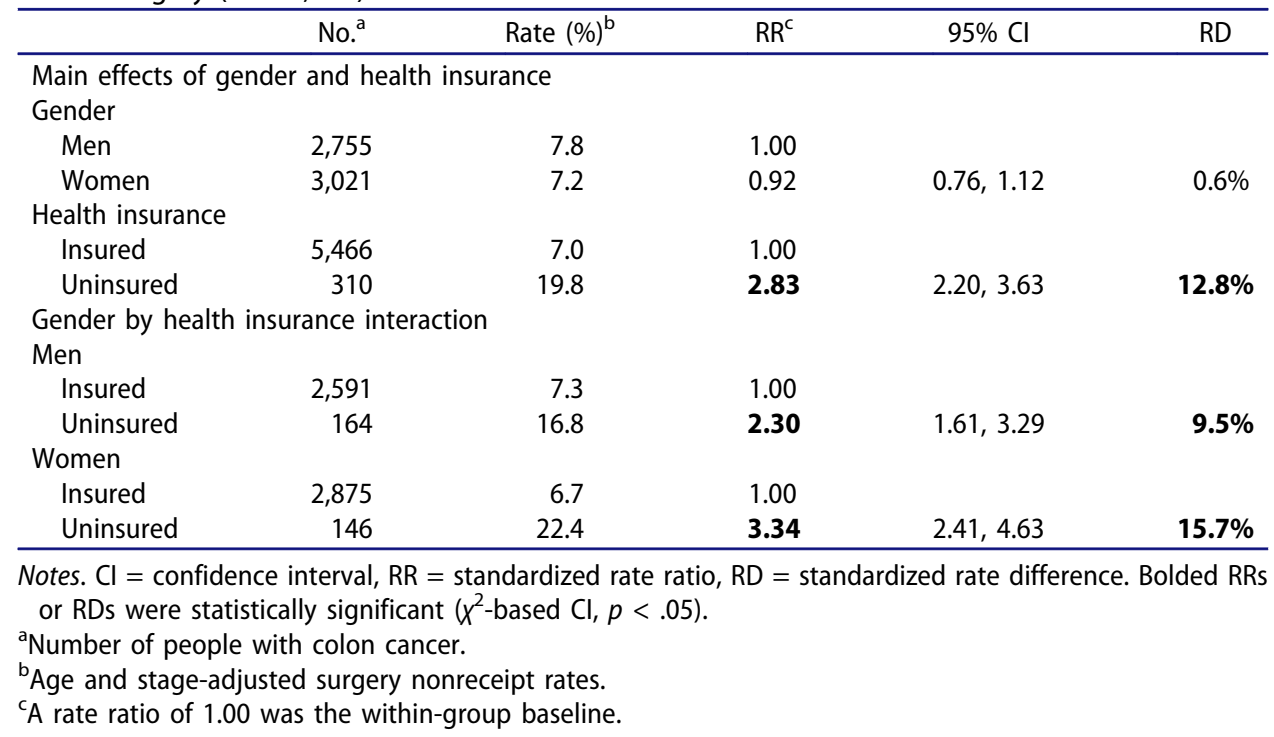




\section{Discussion}

Social work researchers have long called for the study of interaction effects (de Smidt \& Gorey, 1997; Lundahl, Yaffe, \& Hobson, 2009; Videka-Sherman, 1988). This seems convergent with the call of intersectionality theorists for more complex study of interlocking systems of privilege and oppression (Bowleg, 2012; Hulko, 2009). This study demonstrated the contemporary importance of these principles. If this had been a study of mere main effects one might have concluded that gender does not matter. But study of the gender by health insurance interaction showed that gender profoundly matters. Women were more disadvantaged by being uninsured than men in preObamacare America. If Trumpcare becomes law, America's history of allowing such multiplicative disadvantages as we and others have observed among women, people of color, people living in poverty and the inadequately insured are certain to be repeated.

Our findings may not be generalizable to all Americans. But given that one in ten Americans lives in California, they seem to have ample external validity. The original database overrepresented people living in poverty so our findings are most representative of their experiences. Moreover, California expanded its Medicaid program more liberally under Obamacare than most states so estimates of inequities there are probably underestimates of the nation. Also, some of this study's subsamples were modest (146 uninsured women, 164 uninsured men). Still it had ample power to detect its large effects (Fleiss, Levin, \& Paik, 2003). Moreover, other subsamples (2,875 insured women, 2,591 insured men) served as multiple "controls," ensuring statistical power.

\section{Historical note on the present policy considerations}

Rather than replacing the ACA, this study's findings supported its retention and strengthening. For lack of support, the ACA moved many from the ranks of the uninsured to the underinsured. Most private plans purchased through exchanges have been so-called bronze plans with very high deductibles and co-payments and many state Medicaid programs have been similarly compromised (Gorey et al., 2017). All of the Trumpcare iterations would magnify such coverage gaps, essentially making most health insurance plans, private and public, more purchasable, but less usable, especially among people living in poverty or near poverty. Adequately supported exchanges are needed to eliminate the gross inequities in private health insurance plans that range from platinum to bronze. Medicaid ought to be equitably expanded and supported across all states, red and blue. Well-supported Obamacare would reduce health care inequities much more effectively than Trumpcare, but single-payer reform would probably eliminate them. 


\section{Acknowledgements}

We acknowledge the administrative assistance of Kurt Snipes, Janet Bates and Gretchen Agha of the Cancer Surveillance and Research Branch, California Department of Public Health (CDPH) and Dee West and Marta Induni of the Cancer Registry of Greater California (CRGC). We also acknowledge the research or technical assistance of Glen Halvorson, Donald Fong and Arti Parikh-Patel of the CRGC and Madhan Balagurusamy and Nancy Richter of the University of Windsor. Finally, we acknowledge the assistance of Isaac Luginaah and Guangyong Zou of Western University, Eric Holowaty of the University of Toronto, Emma Bartfay of the University of Ontario Institute of Technology, Caroline Hamm and Sindu Kanjeekal of Windsor's Regional Cancer Center and Frances Wright of the Sunnybrook Health Sciences Center in obtaining funding or designing the primary database for this secondary analysis.

The collection of cancer incidence data used in this study was supported by the CDPH as part of the statewide cancer reporting program mandated by California Health and Safety Code; the National Cancer Institute's (NCI) Surveillance, Epidemiology and End Results Program under contracts awarded to the Cancer Prevention Institute of California, the University of Southern California, the Public Health Institute and the Centers for Disease Control and Prevention's (CDCP) National Program of Cancer Registries under an agreement awarded to the $\mathrm{CDPH}$. The ideas and opinions expressed herein are those of the authors and endorsement by the State of California, the CDPH, the NCI or the CDCP or their contractors and subcontractors are not intended or should be inferred.

\section{Declaration of interest}

The authors report no potential conflicts of interest.

\section{Funding}

This research was supported by a grant from the Canadian Institutes of Health Research (grant no. 67161-2) and an Ontario Graduate Scholarship. The funders had no role in study design, data collection and analysis, decision to publish or preparation of the manuscript.

\section{ORCID}

Amy M Alberton (iD http://orcid.org/0000-0002-4746-0704

Kevin M Gorey (ib) http://orcid.org/0000-0003-1870-6549

\section{References}

Bowleg, L. (2012). The problem with the phrase women and minorities: Intersectionality-An important theoretical framework for public health. American Journal of Public Health, 102 (7), 1267-1273. doi:10.2105/AJPH.2012.300750

Campbell, D., Gorey, K. M., Luginaah, I. N., Zou, G., Hamm, C., \& Holowaty, E. J. (2016). Gender differences on the interacting effects of marital status and health insurance on long-Term colon cancer survival in California, 1995-2014. Public Health, 140, 258-260. doi:10.1016/j.puhe.2016.07.008

De Smidt, G. A., \& Gorey, K. M. (1997). Unpublished social work research: Systematic replication of a recent meta-analysis of published intervention effectiveness research. Social Work Research, 21(1), 58-62. doi:10.1093/swr/21.1.58 
DeNavas-Walt, C., Proctor, B. D., \& Smith, J. C. (2011). US Census Bureau, Current Population Reports (P60-245). In L. Chen, D. Gillis, J. S. Sweeney, J. A. Stark, \& F. Hall (Eds.) Income, poverty and health insurance coverage in the United States, 2010. Washington, DC: US Government Printing Office.

Fleiss, J. L., Levin, B., \& Paik, M. C. (2003). Statistical methods for rates and proportions (3rd ed.). New York, NY: John Wiley \& Sons.

Gorey, K. M., Hamm, C., Luginaah, I. N., Zou, G., \& Holowaty, E. J. (2017). Breast cancer care in California and Ontario: Primary care protections greatest among the most socioeconomically vulnerable women living in the most underserved places. Journal of Primary Care \& Community Health, 8(3), 127-134. doi:10.1177/2150131916686284

Gorey, K. M., Holowaty, E. J., Fehringer, G., Laukkanen, E., Moskowitz, A., Webster, D. J., \& Richter, N. L. (1997). An international comparison of cancer survival: Toronto, Ontario, and Detroit, Michigan, metropolitan areas. American Journal of Public Health, 87(7), 11561163. doi:10.2105/AJPH.87.7.1156

Gorey, K. M., Kanjeekal, S. M., Wright, F. C., Hamm, C., Luginaah, I. N., Bartfay, E., \& Richter, N. L. (2015). Colon cancer care and survival: Income and insurance are more predictive in the USA, community primary care physician supply more so in Canada. International Journal for Equity in Health, 14, 109. doi:10.1186/s12939-015-0246-Z

Gorey, K. M., Luginaah, I. N., Bartfay, E., Fung, K. Y., Holowaty, E. J., Wright, F. C., \& Kanjeekal, S. M. (2011). Effects of socioeconomic status on colon cancer treatment accessibility and survival in Toronto, Ontario, and San Francisco, California, 1996-2006. American Journal of Public Health, 101(1), 112-119. doi:10.2105/AJPH.2009.173112

Gorey, K. M., Luginaah, I. N., Bartfay, E., Zou, G., Haji-Jama, S., Holowaty, E. J., \& Richter, N. L. (2013). Better colon cancer care for extremely poor Canadian women compared with American women. Health \& Social Work, 38(4), 240-248. doi:10.1093/hsw/hlt022

Gorin, S. H. (2017). The future of the patient protection and affordable care act. Health \& Social Work, 42(1), 5-6. doi:10.1093/hsw/hlw063

Hosmer, D. W., Lemeshow, S., \& Sturdivant, R. X. (2013). Applied logistic regression (3rd ed.). New York, NY: John Wiley \& Sons.

Hulko, W. (2009). The time- and context-contingent nature of intersectionality and interlocking Oppressions. Affilia: Journal of Women and Social Work, 24(1), 44-55. doi:10.1177/0886109908326814

Keller, D. M., Peterson, E. A., \& Silberman, G. (1997). Survival rates for four forms of cancer in the United States and Ontario. American Journal of Public Health, 87(7), 1164-1167. doi:10.2105/AJPH.87.7.1164

Levitz, N. R., Haji-Jama, S., Munro, T., Gorey, K. M., Luginaah, I. N., Bartfay, E., \& Holowaty, E. J. (2015). Multiplicative disadvantage of being an unmarried and inadequately insured woman living in poverty with colon cancer: Historical cohort exploration in California. BMC Women's Health, 15, 8. doi:10.1186/s12905-015-0166-5

Lundahl, B., Yaffe, J., \& Hobson, J. (2009). Today's studies, tomorrow's meta-analyses: Implications for evidence informed decision-making in social work. Journal of Social Service Research, 35(1), 1-9. doi:10.1080/01488370802473807

National Association of Social Workers. (2009). Health care policy. In Social work speaks: National Association of Social Workers Policy Statement 2009-2012 (8th ed., pp. 167-170). Washington, DC: NASW Press.

Videka-Sherman, L. (1988). Metaanalysis of research on social work practice in mental health. Social Work, 33(4), 325-338.

Wilson, W. J. (2012). The truly disadvantaged: The inner city, the underclass, and public policy (2nd ed.). Chicago, IL: University of Chicago Press. 